\title{
Os projetos de investigação e a educação de jovens e adultos: desenvolvendo a autonomia intelectual
}

Ricardo Carlos Bins Neto* Talita Sganderla Chesini ${ }^{* *}$

Resumo: A Educação de Jovens e Adultos (EJA) possui características próprias, as quais priorizam o uso de determinadas práticas didáticas. A metodologia dos projetos de investigação, a qual se embasa nos preceitos teóricos do educar pela pesquisa, mostra-se propícia aos objetivos da EJA. Ao construírem conhecimento por meio do método científico, os alunos exercitam a autonomia intelectual, o que contribuirá para o seu desenvolvimento cognitivo e inserção no mundo social e do trabalho.

Palavras-chave: Pesquisa, EJA, Autonomia intelectual.

Abstract: The Education of Teenagers and Adults (EJA, in Portuguese) has its own characteristics, which prioritize the use of some didactics' practices. The methodology of investigation projects, which is structured within the precepts of teaching by research theory, has shown itself as propitious to the purpose of the EJA. Using the scientific method to build knowledge, our students exercise their intellectual autonomy, what contributes to their cognitive development and insertion in social and work worlds.

Keywords: Research, EJA, Intellectual autonomy.

${ }^{*}$ Mestre em Educação em Ciências e professor da Rede Municipal de Ensino de Porto Alegre. E-mail: ricardobins83@gmail.com

** Licencianda em Ciências Biológicas. E-mail: talizinhaa89@hotmail.com 


\section{Introdução}

Desde seus primórdios, a Educação de Jovens e Adultos (EJA) possui características próprias, sejam elas epistemológicas, metodológicas ou referentes aos objetivos gerais dos processos de ensino e de aprendizagem. No que diz respeito aos conceitos, competências e habilidades a serem desenvolvidas na EJA, concordamos com Lima e Paaz (2006, p. 137) quando afirmam que

a seleção dos conteúdos deve deixar de privilegiar apenas os conteúdos conceituais, referentes a fatos, conceitos e fenômenos que ocorrem no mundo natural, e reconhecer a importância de conteúdos procedimentais - solução de problemas, aplicação dos conceitos estudados em outros contextos, a busca de informação em diferentes fontes - e de conteúdos atitudinais, que envolvem aprendizagens essenciais para a tomada de posição crítica sobre atitudes e valores determinantes de qualidade de vida, individual e coletiva.

Muito mais do que promover a alfabetização e a aquisição de novos conhecimentos por parte de uma parcela da sociedade que, por motivos diversos, não teve a oportunidade de frequentar o ensino normal, a EJA visa principalmente o desenvolvimento pleno das capacidades cognitivas desses sujeitos. Dessa forma, contribuir-se-á para a melhoria das suas condiçôes de vida, assim como para sua inserção efetiva no mundo do trabalho.

Com base nessas considerações, viemos aqui dissertar sobre a importância de lançarmos novos olhares sobre os processos didáticos desenvolvidos na EJA, a fim de adequá-los às características desta modalidade de ensino. Acreditamos estar implícita a importância de uma prática docente competente, comprometida, assim como a necessidade do planejamento de atividades capazes de contribuir de modo efetivo para a educação e inserção do aluno jovem e adulto no mundo social e do trabalho. 


\section{Características epistemológicas do aluno jovem e adulto}

A grande maioria dos alunos da EJA possui uma grande experiência de vida, chegando à sala de aula com uma significativa bagagem de conhecimentos prévios. As propostas didáticas desse nível de ensino devem, portanto, embasar-se principalmente no processo de validação ou reconstrução desses conhecimentos prévios, aproximando assim os conhecimentos empíricos - oriundos principalmente da vivência dos discentes - daqueles ditos científicos, os quais são construídos principalmente por meio da ação docente.

Os conhecimentos prévios são um corpo organizado de idéias e modelos mentais oriundos da interação do indivíduo com o mundo (ASTOLFI, 1988; DE LA GÁRDARA et al., 2002). Eles expressam a forma como cada um interpreta e compreende os fenômenos da realidade, independente de uma instrução formal recebida. Nos processos de ensino e de aprendizagem esses conhecimentos prévios têm grande importância, especialmente para o professor, pois conforme Astolfi (1988), a aquisição de conceitos pelos alunos não é mero preenchimento de um espaço vazio, mas sim a reconstrução de um corpo organizado de ideias e concepções prévias.

É por isso que os professores que, em sala de aula, consideram e trabalham com essas ideias prévias, respeitam a dinâmica dos processos didáticos, identificando nas concepções dos alunos tanto 'obstáculos' - modos de pensar e proceder contrários à construção de determinado saber - como 'precursores' - ideias que se aproximam do saber a ser construído - (COELHO et al., 2000).

Conforme Vital Junior (2006), os espaços destinados à EJA cumprem, entre outros, o papel de mediar saberes cotidianos e conhecimento formal. É essencial então que o professor da EJA priorize constantemente o objetivo de sempre colocar em foco de discussão as concepções dos indivíduos do grupo em relação aos diferentes assuntos trabalhados em sala de aula. Como, porém, promover tal mediação? Tal indagação nos leva a dissertar sobre 
uma metodologia didática que, em virtude das características epistemológicas descritas até agora, mostra-se mais que apropriada à EJA: o educar pela pesquisa.

\section{O educar pela pesquisa e o ciclo do questionamento reconstrutivo}

As propostas didáticas que se fundamentam no referencial teórico do educar pela pesquisa (MORAES; GALIAZZI; RAMOS, 2004) têm como característica marcante justamente o objetivo de sempre colocar, no foco de discussão, as concepções dos indivíduos do grupo em relação aos temas discutidos. Este estímulo visa essencialmente a dar início ao movimento dialético tido como princípio fundamental de tais propostas, denominado ciclo do questionamento reconstrutivo e composto de três momentos principais (Fig. 1) que se alternam.

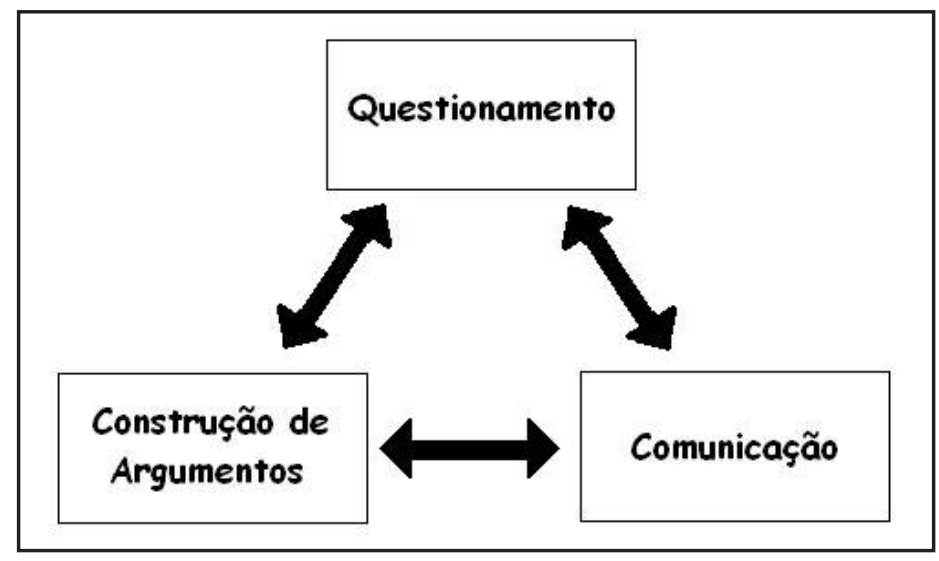

Fig l. Momentos do educar pela pesquisa.

No primeiro momento, o do questionamento em si, o conteúdo a ser trabalhado com o grupo de alunos é problematizado, e 
os sujeitos são estimulados a exteriorizarem e a expressarem as suas concepções prévias acerca do tema. Em seguida, essas concepções são submetidas à crítica dos envolvidos no processo e novos argumentos são construídos pela validação ou reconstrução dessas ideias prévias. Os novos argumentos são então esquematizados em novas concepções sobre o tema. A divulgação dessas novas concepções, para além dos limites do grupo inicial, na etapa chamada de comunicação dos resultados, possibilita sua análise crítica por outros sujeitos, iniciando-se assim novamente o ciclo de questionamento.

Ao exercitar nos alunos as habilidades da crítica e do diálogo, assim como a capacidade de ponderar entre diferentes argumentos, muitas vezes contraditórios, contribui-se para o desenvolvimento de importantes aspectos constituintes de sua autonomia intelectual. O desenvolvimento dessa autonomia intelectual é de extrema importância ao aprimoramento da capacidade cognitiva de cada discente, pois, segundo Demo (2002, p. 124):

Saber pensar começa, primeiro, com a habilidade de autocrítica: saber o quão pouco se sabe, reconhecer os limites do conhecimento, avaliar os desmandos históricos do conhecimento, formular o sentido de responsabilidade ética nas intervençôes feitas pelo conhecimento.

Determinados nossos pressupostos teóricos, dissertaremos agora sobre uma dentre as diversas metodologias didáticas embasadas nos preceitos do educar pela pesquisa, a qual vem sendo trabalhada na EJA desenvolvida no Colégio de Aplicação da Universidade Federal do Rio Grande do Sul (CAp/UFRGS), com as duas etapas correspondentes às séries finais do Ensino Fundamental, assim como as três etapas correspondentes à totalidade do Ensino Médio: os Projetos de Investigação (PI).

\section{Os Projetos de Investigação: construindo conhecimento de forma científica}

No CAp/UFRGS, os PI são desenvolvidos semestralmente com cada uma das etapas da EJA anteriormente citadas. Nesses 
projetos, cada aluno desenvolve, ao longo do semestre, uma pesquisa acerca de determinado tema. Embora sejam estruturados grandes eixos temáticos norteadores, a escolha do tema a ser pesquisado, dentro desses grandes eixos, parte do interesse do próprio aluno, que começa sua pesquisa determinando qual a pergunta inicial de sua pesquisa. Em seguida elabora-se uma justificativa ao interesse em obter uma resposta a essa pergunta, assim como uma hipótese inicial a tal indagação. Posteriormente, conforme os PI são desenvolvidos, os alunos seguem estruturando novas perguntas secundárias, pertinentes ao tema investigado.

Após a estruturação inicial do PI, os alunos são divididos em pequenos grupos, e cada grupo é tutorado por um ou mais professores. A principal função dos tutores ao longo do desenvolvimento dos PI é o auxílio aos alunos durante esse processo, indicando, por exemplo, fontes confiáveis de consulta, ou solucionando problemas - obstáculos que os alunos não conseguiram transpor por si próprios - de diferentes naturezas, como dúvidas cujas respostas não foram localizadas ou elaboradas independentemente pelos discentes. Também é uma importante função do tutor o acompanhamento de todo processo de pesquisa do aluno, para a sua posterior avaliação.

Cabe-se ressaltar o caráter interdisciplinar dessa estratégia de ensino, pois os temas escolhidos naturalmente permeiam as diferentes disciplinas escolares, e é comum que em diversos momentos os alunos peçam algum auxílio a outros professores, que não os tutores de seu próprio grupo.

É também nos PI que se destaca a integração das novas tecnologias de informação e comunicação. A rede mundial de computadores mostra-se uma significativa fonte de consulta para suas pesquisas, residindo aí outra importante função do professor como tutor. Sabe-se que praticamente não há controle acerca da veracidade das informaçôes encontradas na rede, e o tutor deve então continuamente orientar seus alunos sobre os sites que podem ser considerados confiáveis.

Muito mais do que a introdução dos alunos ao método científico por meio da estruturação de uma pesquisa embasada na 
construção de perguntas de investigação e elaboração e teste de hipóteses, a execução dos PI torna-se, entretanto, extremamente relevante por estimular nos discentes o desenvolvimento de uma importante habilidade cognitiva já mencionada anteriormente: a autonomia intelectual, indispensável na sua formação como indivíduos.

Ao desenvolverem por si próprios uma investigação acerca de determinado tema, primeiramente os alunos dão um importante passo na direção de deixarem de ser meros objetos dentro do processo educativo, estruturando-se como sujeitos responsáveis pelo seu próprio aprendizado. Um dos pilares da Educação, afinal de contas, segundo o Relatório Delors, elaborado pela Organização das Nações Unidas para a Educação, a Ciência e a Cultura (UNESCO), é o aprender a ser:

Todo ser humano deve ser preparado para a autonomia intelectual e para uma visão crítica da vida, de modo a poder formular seus próprios juízos de valor, desenvolver a capacidade de discernimento e como agir em diferentes circunstâncias da vida (WERTHEIN, 2005, p. 23).

O desenvolvimento da autonomia intelectual dos alunos também é indispensável na formação de sujeitos atuantes socialmente. Há tempos em que a Educação não tem mais como único objetivo transmitir conhecimentos e disciplinar os alunos nem, tampouco, fornecer uma única formação técnica e profissionalizante, como ocorreu nos períodos da grande industrialização (BLONDEL, 2005). Historicamente, o ensino escolar também adquiriu a importante função de formar cidadãos. E conforme argumentam Castro e Baeta (2005, p. 106), "a escola, por intermédio da cooperação e do favorecimento da construção da autonomia intelectual, poderá construir um sujeito capaz de exercer a sua cidadania”.

Por fim, a metodologia dos PI também se mostra promissora no que diz respeito à socialização dos conhecimentos construídos individualmente. Isso porque ao final de cada semestre é organizado um fórum de apresentação dos PI, momento no qual cada aluno apresenta ao restante da comunidade escolar os resultados obtidos no seu PI. A última etapa do ciclo do questionamento reconstrutivo, a de comunicação dos resultados, desenvolve-se neste momento. 


\section{Conclusões}

O que procuramos discutir neste breve artigo teórico é a significância de uma prática docente embasada nos preceitos do educar pela pesquisa na EJA. Um trabalho didático embasado no questionamento construtivo, primeiramente, promove a aproximação dos saberes cotidianos dos formais, além de exercitar, por parte dos alunos, a construção de conhecimento por meio do método científico.

Além disso, os PI possibilitam o exercício da autonomia intelectual do aluno, o que possibilitará a sua mudança de objeto a sujeito no processo de aprendizagem, contribuindo também para a sua formação como cidadão. Para que cada um de nós tenha voz ativa na sociedade, é preciso que saibamos que não há verdade pronta e absoluta, e que tudo pode ser questionado. Se assim pensarmos, não mais aceitaremos de forma submissa qualquer conceito ou ideologia que muitas vezes nos são impostos por aqueles que, de diferentes formas, buscam atrelar grilhões ao nosso pensamento. Muitas vezes uma grande mudança inicia-se com uma simples e pequena pergunta: por quê?

\section{Referências}

ASTOLFI, Jean-Pierre. El aprendizaje de conceptos científicos: aspectos epistemológicos, cognitivos y lingüísticos. Enseñanza de las Ciências, v. 6, n. 2, p. 147-155, 1988.

BLONDEL, Daniele. Dificuldades, Riscos e Desafios do Século XXI. Delors, Jacques (Org.). A educação para o século XXI: questôes e perspectivas. Porto Alegre: Artmed, 2005.

CASTRO, Ronaldo Souza de; BAETA, Anna Maria Bianchini. AUTONOMLA INTELECTUAL: condição necessária para o exercício da cidadania. In: LOUREIRO; Carlos Frederico B.; LAYRARGUES, Philippe Pomier; CASTRO, Ronaldo Souza de (Orgs.). Educação Ambiental: repensando o espaço da cidadania. São Paulo: Cortez, 2005. 
COELHO, Suzana Maria et al. Conceitos, atitudes de investigação e metodologia experimental como subsídio ao planejamento de objetivos e estratégias de ensino. Caderno Catarinense de Ensino de Física, v. 17, n. 2, p. 122-149, ago. 2000.

DE LA GÁNDARA, Milagros et al. Del modelo científico de "adaptación biológica" al modelo de "adaptación biológica" em los libros de texto de enseñanza secundaria obligatoria. Enseñanza de las Ciências, v. 20, n. 2, p. 303-314, 2002.

DEMO, Pedro. Pesquisa e construção de conbecimento: metodologia científica no caminho de Habermas. 5 ed. Rio de Janeiro: Tempo Brasileiro, 2002. 125p.

LIMA, Valderez Marina do Rosário; PAAZ, Aneli. Reflexões sobre o ensino de Ciências na Educação de Jovens e Adultos. Ciências \& Letras - Educação de Jovens e Adultos. n. 40 Porto Alegre: Faculdade Porto-Alegrense de Educação, jul./dez. 2006.

MORAES, Roque; GALIAZZI, Maria do Carmo; RAMOS, Maurivan Günter. Pesquisa em sala de aula: fundamentos e pressupostos. In: MORAES, Roque.; LIMA, Valderez Marina do Rosário (Orgs.). Pesquisa em sala de aula: tendências para a educação em novos tempos. 2. ed. Porto Alegre: EDIPUCRS, 2004.

VITAL-JUNIOR, Raul Rebello. A interdisciplinaridade na educação de jovens e adultos. In: Ciências \& Letras - Educação de Jovens e Adultos. n. 40 Porto Alegre: Faculdade Porto-Alegrense de Educação, jul./ dez. 2006

WERTHEIN, Jorge. Fundamentos da nova educação. 5 ed. Brasília: Unesco, 2005. 81p. 